\title{
Pure science in an age of attrition
}

Despite stupendous advances in the past $\mathbf{5 0}$ years, Western governments' support of research for its own sake is on the wane. The new year is an appropriate time for researchers and policy-makers to consider the implications and make some resolutions.

LONG gone are the days when society perceived the scientist as someone pursuing simply and exclusively, to use Samuel Taylor Coleridge's phrase, the "gratification of knowing". The 50 years since the end of the Second World War, especially, have seen continual tension between scientists and politicians about the linkage between the exploration of natural (and sometimes unnatural) phenomena on the one hand and their countries' interests on the other. The multinational survey of the period in this issue (see pages 5-9) reflects some of those tensions. But a look forward suggests that the lessons of history are not sufficient to cope with problems that are to come, and that original and sometimes unpleasant thinking is required on behalf of pure science in particular.

Regrettably, there are moral overtones to the word "pure" "basic" is more neutral. But those who attain fulfilment merely from asking careful questions of the world and sometimes having them interestingly answered - at best, in a totally unexpected fashion - know the essential purity of the experience. With that comes a motivation, if not a compulsion, quite distinct from the determination to invent, to create wealth or to enhance the quality of life. But if scientists then find that they have new knowledge or experience to exploit, and enjoy the prospect of moving out of research to enrich society (and perhaps themselves) and leave openings for other bright young things, all well and good.

The fact that most good scientists do not behave like that gives rise to acute pain and much distraction if the budget for pure science is contracting - which, in too many countries, it is. In Japan and Germany funds are officially expanding, but governments are finding it hard to deliver on their promises. But there are many countries where researchers are finding more and more frequently that high quality, non-strategic ideas that are not immediately applicable fail to attract funds. This trend will continue for some time to come, given the increasingly stressed state of most industrial economies, combined with a correct but imbalanced perception by governments that strategic and immediately applicable ideas are important for international competitiveness.

The central political issues for scientists engaged in research for its own sake are therefore twofold: first, to fight back by seeking to ensure that governments' perceptions of the importance of their work are well founded; and second, to minimize the damage inflicted by declining resources. Although these challenges are not new to some disciplines, the pressures to come necessitate more radical responses than hitherto.

The first challenge requires greater cohesion between scientists, economists and analysts of science and technology policy, not least by talking to each other more. Mutual awareness is at present too often fragmentary. Improved contacts are necessary in order to illuminate the benefits to a modern economy of vigorous activities in pure sciences - benefits in skills and creative flexibility of key portions of the population, in education, in attracting inward investment, past benefits that were unanticipated products of basic research, and benefits in culture (which also contribute positively to economies).
This is not to request a bending of economics and policy research to the scientists' policy agenda, but rather to make the most of them. And presenting a case for basic science in a sophisticated economic context can only strengthen its call on politicians' attention - especially if weaknesses in assumptions underlying an imbalance in support for applied science are also exposed. An important side issue here is to ensure that statistics of support for distinctively basic research are adequately maintained.

Fighting back also requires the development of political skills, so as to present the case more effectively than at present. Last year, for example, saw US biologists outshine physicists in protecting their budgets from political onslaught. Physicists were belatedly urged by professional bodies to write to their representatives in Congress. More generally, scientists need to question whether they can be sufficiently represented by learned societies in today's politics (to which the answer is no) and to do more to channel complementary representation through respectable lobby groups, funded from scientists' own pockets, and, even more than now, through the media.

The second challenge confronts basic researchers with a need for more collaborative funding and coordination. In a contracting financial universe, costly particle physics and space-based sciences especially face a need to sacrifice national aspirations to the overriding interests of internationalism. It is worrying that, with research and development towards the world's nextbut-one major accelerator well under way, and despite the efforts of the OECD's Megascience Forum, decisions to build intermediate-size facilities (such as B-boson factories) are still being taken at a national level without adequate international planning. Similarly Japan, Europe and the United States urgently need to perceive their futures in space-based sciences as more fundamentally collaborative than has ever been the case in the past.

'Small science' will also require more internationalism in a way that challenges the interests of national funding agencies. In pure science, the people who need to be funded are simply the best, wherever they are. It is better, therefore, to ensure that, for example, several European countries support two excellent research centres in a hopelessly inapplicable patch of basic science than to allow the activity to fade out of Europe altogether. The need to institutionalize collaboration in European science funding well beyond the activities of the European Commission has never looked stronger.

Most challengingly of all, limiting the damage from declining funds also requires something of excellent scientists that is deeply impure: to sit on committees and, again and again, to be prepared to identify other excellent scientists who, for budgetary reasons only, must receive no more funds, occasionally in the process wiping out another subdiscipline within their country. No wonder some funding bodies have recently introduced anonymity of their peer-review panels. But however painful, such eliminations are best carried out by people who understand the damage they are causing — and who do not have to keep silent about it. 